\title{
"AQUIHUECÓ": UN CEMENTERIO ARQUEOLÓGICO, EN EL NORTE DE LA PATAGONIA, VALLE DEL CURI LEUVÚ - NEUQUÉN, ARGENTINA
}

\author{
CLAUDIA E. DELLA NEGRA ${ }^{1}$ Y PAULA S. NOVELLINO ${ }^{2}$
}

\section{RESUMEN}

En el presente artículo se informa sobre los primeros resultados del sitio Aquihuecó, valle del Curi Leuvú, en Norpatagonia Argentina. El hallazgo corresponde a un número mínimo de 32 individuos asociados a material arqueológico. El sitio cuenta con un fechado de $3.650 \pm 70$ años AP (LP-1418).

PALABRAS CLAVES: Cementerio, Bioarqueología, Lítico, Norpatagonia, Rescate Arqueológico.

\section{"AQUIHUECÓ": AN ARCHAEOLOGICAL CEMETERY, ON THE NORTH OF THE PATAGONIA, IN CURI LEUVÚ VALLEY - NEUQUÉN, ARGENTINE}

\begin{abstract}
This paper reports the first results from the Aquihuecó archaeological site, at the Curi Leuvú valley, Northern Argentinean Patagonia. This site consists of at least 32 skeletons associated to archaeological remains. The site has been dated to $3.650 \pm 70$ years BP (LP-1418).

KEY WORDS: Cemetery, Bioarchaeology, Lithic, Northern Patagonia, Archaeological rescue.

\section{INTRODUCCIÓN}

El objetivo de este trabajo es informar sobre los hallazgos realizados en el cementerio precerámico Aquihuecó, localizado en el norte de la provincia del Neuquén, fechado en $3650 \pm 70$ años AP (LP1418). Este es el sitio más antiguo conocido con

la presencia de varios entierros en el noroeste de la Patagonia. En el mismo valle, sobre la margen opuesta del río Curi Leuvú, hemos trabajado en años anteriores un cementerio de contacto hispano indígena, Caepe Malal (Hajduk y Biset 1991, 1996; Hajduk 1993-94, 1997-98, 1999-2000, Vasallo et al. 1996, Hajduk et al. 2000).

1 Dirección General de Patrimonio, Dirección Provincial de Archivos y Patrimonio Cultural, Secretaría de Estado de Cultura, Gobierno de la Provincia del Neuquén. Vuelta de Obligado 50 - Ex Estación de Ferrocarril. (8300) Neuquén. Argentina. E-mail: dellanegra@neuquen.gov.ar

2 CONICET- Consejo Nacional de Investigaciones Científicas y Tecnológicas (CONICET) - Museo de Historia Natural de San Rafael. Parque M. Moreno s/nº. (5600) San Rafael, Mendoza. Argentina. E-mail: pnovel@hotmail.com
\end{abstract}




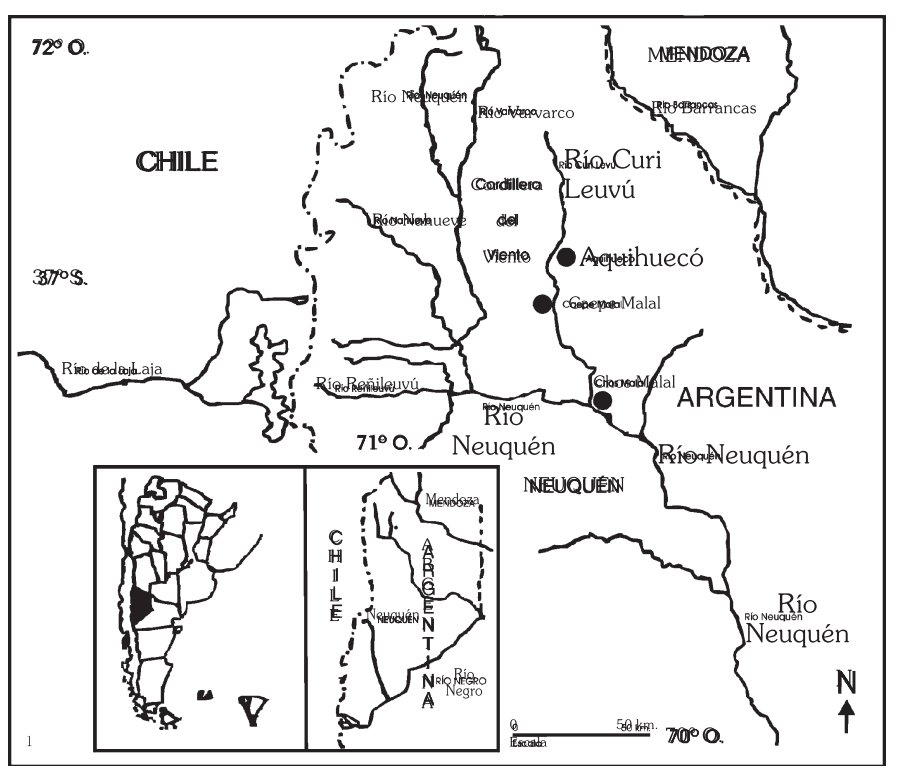

Fig. 1. Mapa de localización del sitio.

El sitio Aquihuecó está situado a 500 m de la margen izquierda del río Curi Leuvú, en la base del Cerro Negro; frente al paraje homónimo, que está localizado a $40 \mathrm{~km}$ al norte de la capital del departamento Chos Malal, noroeste de la provincia del Neuquén, Norpatagonia Argentina (Fig. 1).

Las fuentes de agua más próximas son el mencionado río Curi Leuvú, afluente del río Neuquén y los arroyos Aquihuecó, Nireco y Liuco; todos de régimen permanente y con grandes variaciones en sus caudales. Los valles fluviales son utilizados por la población rural actual como zona de invernada para pastoreo, trasladándose en verano con el grueso de sus rebaños hacia los faldeos montañosos orientales de la Cordillera de los Andes, a través de la Cordillera del Viento.

Desde el punto de vista dinámico, el área es seca y calurosa en verano; fría y húmeda en invierno, con precipitaciones pluviales y nivales. La intensidad de las lluvias es de aproximadamente $150 \mathrm{~mm}$ anuales. La amplitud térmica es de aproximadamente de $10^{\circ} \mathrm{C}$. La acción erosiva del agente eólico es importante con vientos predominantes del sector noroeste. Cabe destacar que Schäbitz marca que el inicio de las condiciones climáticas actuales se ubicaría entre los 3500-4000 años AP (Schäbitz, 1994 en: Zárate 2002: pp 17-18) con algunas fluctuaciones y tendencias a climas cada vez más cálidos determinando el retroceso de los glaciares a su posición actual (Stingl y Garleff 1985 en: Zárate 2002: 21).

La vegetación es xerófila, correspondiente al Distrito Occidental de la Provincia Fitogeográfica Patagónica; algunas de cuyas especies predominantes son: jarilla (Larrea divaricota), molle (Acordeacea schinus), pichana (Psila sparticides), colihuay (Collihuaja integerrima) y neneo o chila (Mullín spinosum). En la fauna actual se puede mencionar la presencia de puma (Felis concolor), zorro colorado (Dusicyon culpaeus), zorro gris (Dusicyon griseus), coipo (Myocastor coypus), piche (Zaedyus pichiy), peludo (Chaetophractus villosus), guanaco (Lama guanicoe) y ñandú (Rhea americana).

El sitio está ubicado en las coordenadas $37^{\circ}$ 05' 29" latitud sur y $70^{\circ} 22^{\prime} 30,5^{\prime \prime}$ longitud oeste (obtenida por GPS plus III "GARMIN") y a 1197 ms$\mathrm{nm}$. Se encuentra emplazado en la porción superior de un médano, ocupando un área de 1.873,72 $\mathrm{m}^{2}$ (55,6 $\mathrm{m}$ x 33,7 m). El sedimento es arenoso y muy friable, pero los arbustos los retienen, preservándolo de la erosión.

Las tareas de rescate en el sitio se desarrollaron en el marco del Proyecto "Rescate del patrimonio arqueológico del norte neuquino", y del Programa de Atención de Denuncias de la actual Secretaría de Estado de Cultura que, en su carácter de Autoridad de Aplicación de la Ley Provincial 2184/96 de "Protección del Patrimonio Histórico, Arqueo- 
lógico y Paleontológico", realizó la denuncia de la presencia de restos óseos humanos en el Paraje Aquihuecó. A raíz de la misma, en marzo de 1997 se realizó el primer reconocimiento en el sitio. En abril del año 2003, el Escuadrón 30 "Chos Malal" de la Gendarmería Nacional Argentina, realizó la denuncia del hallazgo de restos óseos humanos en tierras del señor Félix Méndez, destacando el hallazgo de varios esqueletos expuestos. En respuesta a esta denuncia, en octubre del 2003, se realizó una nueva campaña, pudiendo verificarse que se trataba del sitio relevado en 1997.

En la campaña de 1997, se realizó un registro fotográfico y recolección superficial en un radio de $100 \mathrm{~m}$ en las áreas de mayor concentración de material arqueológico y restos óseos humanos, considerando ocho sectores para su mejor ordenamiento: norte $(\mathrm{N})$, noroeste $(\mathrm{NW})$, noreste $(\mathrm{NE})$, oeste $(\mathrm{W})$, sur $(\mathrm{S})$, suroeste $(\mathrm{SW})$, sureste (SE) y este (E). Se observó que la mayor concentración de restos humanos, estaba en superficie en los sectores norte y noreste del médano. Allí se realizó una limpieza del perfil del médano y se extrajeron muestras para ser fechadas.

Durante la campaña realizada en octubre del 2003 se detectaron varios esqueletos expuestos en la pendiente norte del médano con material arqueológico asociado a los mismos. El médano presentaba escalonamiento, producto de la erosión eólica. A dos metros por debajo del punto más alto del médano, se hallaron cinco esqueletos correspondientes a cuatro entierros primarios y uno secundario (Entierros I, IV, V, VI y VII); a $30 \mathrm{~cm}$ por debajo de éstos, dos entierros primarios (Entierros II y III). Cabe destacar que en la base del médano se recolectaron piezas óseas aisladas, algunas posiblemente derivadas del desprendimiento de los esqueletos ubicados en los sedimentos superiores.

\section{FECHADO RADIOCARBÓNICO}

La muestra de restos óseos humanos, para realizar el fechado radiocarbónico se extrajo del perfil norte del médano, a 1,90 m de profundidad; donde se observó un estrato, de aproximadamente $30 \mathrm{~cm}$ de espesor, con material óseo humano y una lasca de obsidiana asociada.

La muestra fue tratada por el Laboratorio de Tritio y Radiocarbono (LaTyR) - Consejo Nacional de Investigaciones Científicas y Técnicas CONICET - Universidad Nacional de La Plata. Como resultado de su análisis se obtuvo una edad de $3.650 \pm 70$ años C-14 AP (LP-1418).

\section{DESCRIPCIÓN DE ENTIERROS Y CARACTERIZACIÓN BIOARQUEOLÓGICA}

La muestra fue tratada como osario al momento de ser estudiada para determinar el número mínimo de individuos (NMI) considerando que la mayor parte de los restos óseos fueron recuperados en superficie, cayéndose del estrato donde estaban depositados originalmente en el perfil del médano y por lo tanto, en varios casos, impidiendo ser asignados a un determinado entierro.

Luego de las tareas de limpieza, determinación de piezas y fragmentos, curadoría y remontaje, se procedió al conteo de piezas esqueletales con el fin de determinar el NMI total de la muestra de las dos campañas, que correspondió a treinta y dos individuos, compuesto por diecisiete adultos y quince subadultos.

El conjunto de restos óseos recuperados durante la campaña de 1997, está representado por un NMI de cuatro individuos: un adulto y tres subadultos, desprendidos de los sedimentos superiores del médano. El individuo adulto corresponde a un probable masculino de entre 30 - 49 años de edad. Los subadultos representan a un juvenil de 12-14 años, del cual no se pudo realizar determinación de sexo; y a dos infantiles, uno de 6-7 años y otro de 2-4 años. En ninguna de las partes esqueletales se ha observado signos de patología.

El NMI total de la muestra recuperada en el año 2003 es de veintiocho, compuesto por dieciséis individuos adultos y doce individuos subadultos. El número de adultos se determinó por el número de húmeros presentes; mientras que el de subadultos, por el número de fémures.

Las asignaciones etárea y sexual, se realizaron siguiendo las recomendaciones de Buikstra y Ubelaker (1994: pp 15-38). Debido a la exposición a agentes naturales, muchos de los restos óseos presentan mala conservación, dificultando en varios casos estas determinaciones. En los individuos adultos están representados ambos sexos, contabilizando por lo menos cinco femeninos y cuatro masculinos; así como también al menos dos individuos adultos 
jóvenes, de entre 20 y 35 años de edad. Entre los individuos subadultos están representados distintos grupos etáreos: perinatos, 1-3 años, 3-6 años, 5-7 años, 12-15 años y 18-20 años.

En referencia al análisis de la salud bucal, cabe destacar que el grupo de adultos presenta desgaste dental muy alto, observándose exposición de la cavidad pulpar en varias piezas dentales. Además se vio la presencia de 6 abscesos labiales en 4 individuos, ocasionados por algún tipo de infección en las piezas dentales de maxilares superiores o mandíbulas.

Por otro lado, se ha encontrado presencia de rebordes osteoartríticos en algunas de las piezas óseas, tales como ciertas carillas articulares distales de costillas, algunas vértebras lumbares y epífisis de peroné. Esto indicaría la presencia de adultos mayores en el sitio, ya que las mismas son degeneraciones propias de individuos con edades avanzadas.

En cuanto a las patologías, se encontró un individuo femenino de 35-49 años que presentaba un caso de osteomielitis bastante importante en la parte distal de la tibia derecha, ocasionado por alguna infección no específica, que podría haberle causado incluso la muerte por complicaciones posteriores e infección generalizada.

En el perfil del médano, se detectaron cinco entierros localizados en un nivel superior (I, IV, V, VI y VII) y a $30 \mathrm{~cm}$ por debajo, un estrato con tres más (I, II y III). Se observaron entierros primarios y secundarios, simples y dobles, mostrando gran variabilidad intra sitio. El sedimento, sumamente friable, no permitió detectar rastros de límites entre fosas (Fig. 2).

ENTIERRO I: Localizado en el extremo occidental del nivel superior. Es un entierro primario, de un

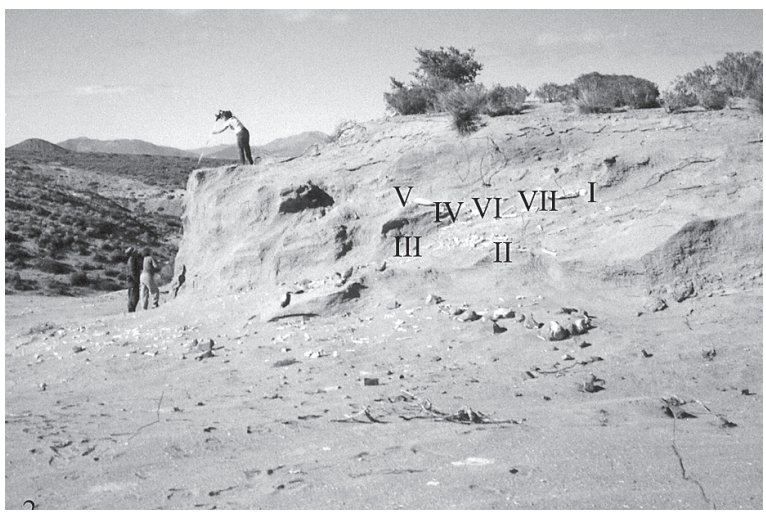

Fig. 2. Foto del médano. individuo juvenil, de 12-15 años de edad. Estaba en posición decúbito dorsal, con su cabeza orientada al oeste y el rostro hacia el sur, los miembros inferiores estaban flexionados y apoyados sobre el costado derecho (Fig. 3).

ENTIERRO II: Estaba localizado $30 \mathrm{~cm}$ por debajo del entierro IV. Es un entierro primario, correspondiente a un individuo juvenil de 18-20 años de edad, en posición decúbito lateral izquierdo, con orientación del cuerpo este-oeste y el rostro hacia el este.

ENTIERRO III: Es un entierro primario. Localizado en el extremo oriental del perfil, $60 \mathrm{~cm}$ por debajo de los entierros VI y V. Es un individuo adulto, de sexo femenino, de 25-45 años de edad. Presentaba una base de molino depositada junto al cráneo.

Junto al entierro III se encontró un individuo infantil, representado por un hueso frontal. El resto de los restos óseos, posiblemente se desprendió por la erosión natural de los sedimentos del médano.

ENTIERRO IV: Localizado al oeste del entierro V, en el nivel de mayor acumulación de restos óseos. Es un entierro primario doble formado por un individuo adulto y uno infantil. Por encima de los miembros inferiores del individuo adulto, se encontraron los restos del infantil. Cabe destacar que tanto sobre la epífisis distal del fémur como sobre la proximal de la tibia izquierda, se observó la presencia de pigmento rojo, el cual también fue recuperado del sedimento asociado al entierro.

Individuo 1: Adulto, de sexo indeterminado y de 35-49 años de edad.

Individuo 2: Infantil menor de tres años.

ENTIERRO V: En el extremo oriental del estrato, se detectaron tres individuos, conformando posiblemente tres entierros primarios, sepultados muy

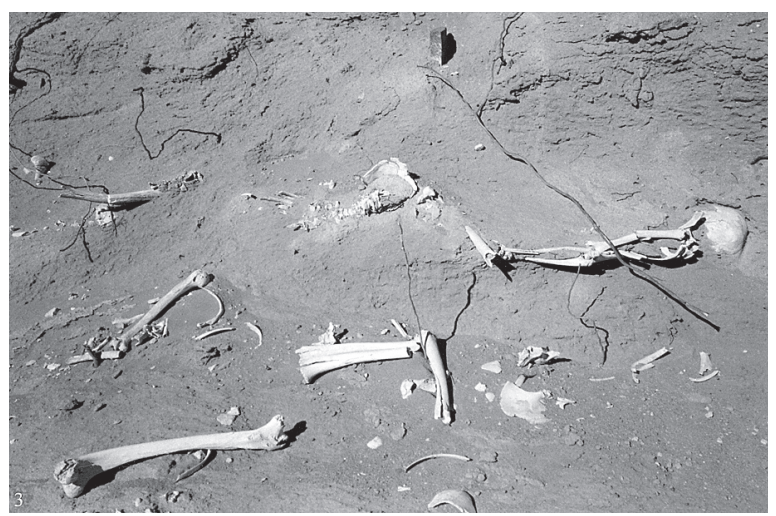

Fig. 3. Entierro I. 


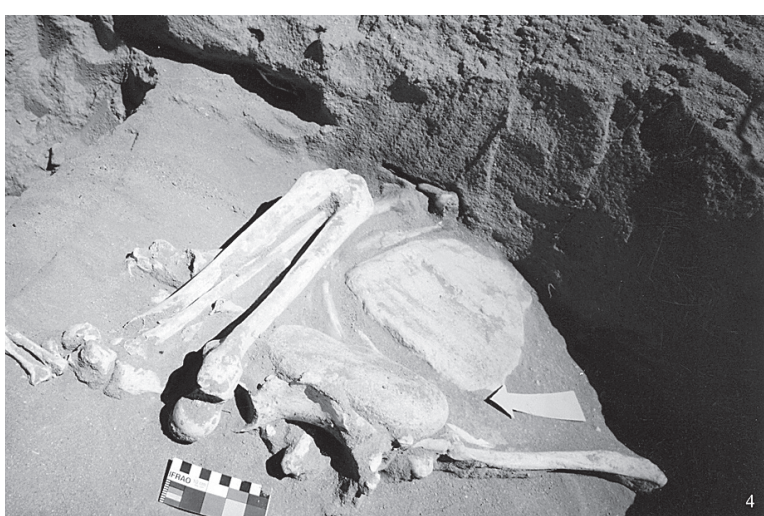

Fig. 4. Entierro V.

cercanos unos a otros, no pudiendo determinarse el grado de contemporaneidad (Fig. 4).

Individuo 1: Juvenil de entre 12 y 18 años de edad, en posición fetal, apoyado sobre su costado derecho, la cabeza estaba hacia el oeste y los pies hacia el este. Asociado a este entierro habían dos bases de molino junto a las extremidades inferiores.

Individuo 2: Infantil de entre 3 y 6 años de edad.

Individuo 3: Infantil de edad indeterminada. ENTIERRO VI: Localizado en el escalón superior, entre los entierros IV y VII.

Corresponde a un entierro secundario de un individuo adulto de sexo masculino de 35-49 años de edad, cuyas extremidades inferiores estaban ubicadas a escasos centímetros del entierro VII.

ENTIERRO VII: En el perfil superior del médano se detectó un entierro primario, en posición decúbito dorsal, con la cabeza orientada al oeste y los pies al este; su rostro hacia el sur. Es un individuo adulto femenino, de 35 a 49 años de edad. Cabe destacar

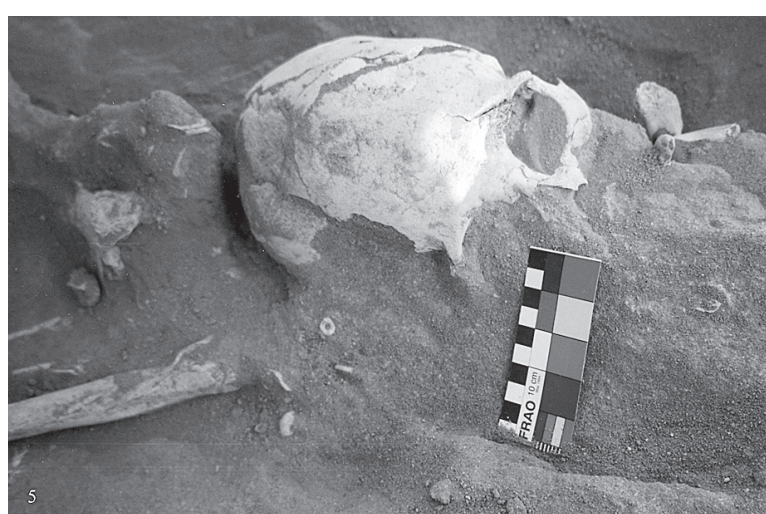

Fig. 5. Entierro VII.

que en el sector del cuello, fueron halladas cuatro cuentas de valvas, las cuales, posiblemente conformarían un collar que tendría puesto al momento de ser enterrado. El cráneo de este individuo presenta una deformación muy marcada, de tipo anular (Fig. 5).

\section{DESCRIPCIÓN DE LOS \\ MATERIALES ASOCIADOS}

Recolección superficial, por sector:

Materiales líticos

Los materiales líticos conforman un grupo de 150 elementos, entre los cuales se destaca la presencia de: cuatro bases de molino con su mano correspondiente, una punta de proyectil, dos preformas de puntas de proyectil, veintisiete instrumentos de filo (cepillos, raspadores, raederas, cuchillos, instrumentos compuestos y lascas con rastros de utilización), diez núcleos y ciento seis desechos de talla.

Tabla 1: Materiales recuperados durante la campaña de 1997.

\begin{tabular}{|c|l|}
\hline SECTOR & \multicolumn{1}{c|}{ MATERIALES } \\
\hline Norte $(\mathrm{N})$ & $\begin{array}{l}\text { Una cuenta de hueso de } 5 \mathrm{~mm} \text { de diámetro, lascas de obsidiana y de sílice, y un instrumento con filo } \\
\text { perimetral. }\end{array}$ \\
\hline Sur (S) & $\begin{array}{l}\text { Tres cuentas de valvas de } 3 \mathrm{~mm} \text { de diámetro, una lasca de basalto, cuatro lascas de obsidiana negra, seis } \\
\text { lascas de cuarzo transparente, tres núcleos de cuarzo blanco, una lasca de cuarzo con rastros de utilización, } \\
\text { una lasca secundaria de obsidiana, una lasca primaria de basalto, un desecho de sílice y tres lascas con } \\
\text { rastros de utilización. }\end{array}$ \\
\hline Sureste (SE) & Dos núcleos de cuarzo lechoso. \\
\hline Suroeste (SW) & Cinco lascas de obsidiana y una lasca de sílice. \\
\hline Oeste (W) & $\begin{array}{l}\text { Hasta 100 m de la acumulación de restos óseos: tres lascas de sílice con rastros de utilización, dos lascas } \\
\text { angulares. }\end{array}$ \\
\hline Este (E) & $\begin{array}{l}\text { Una lasca grande con lascados perimetrales. Se colectaron escasos restos faunísticos, en su mayoría, } \\
\text { pertenecientes a roedores (cráneos y dientes incisivos). }\end{array}$ \\
\hline Perfil Norte & $\begin{array}{l}\text { Restos óseos humanos asociados a lascas y desechos de talla. Muestra de restos óseos humanos utilizada } \\
\text { para fechado radiocarbónico. }\end{array}$ \\
\hline
\end{tabular}




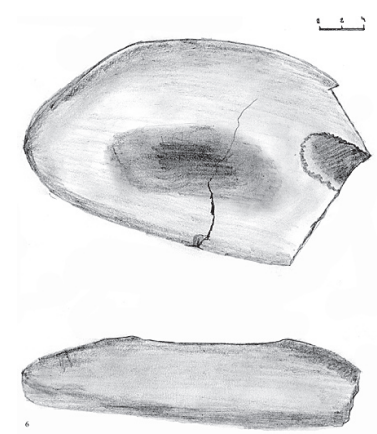

Fig. 6. Molino.

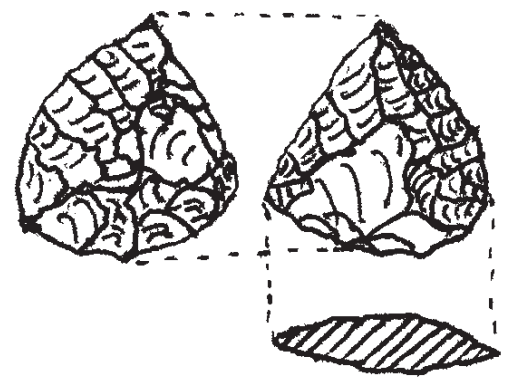

Fig. 7. Punta de Proyectil.

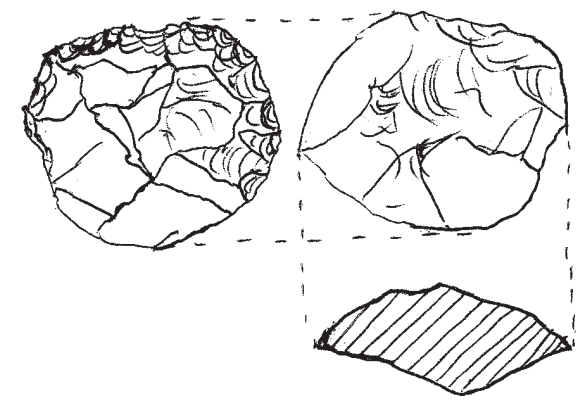

Fig. 8. Raspador.
Una de las manos de moler fue encontrada junto a un molino. La mano es esférica, con las siguientes dimensiones: $102 \mathrm{~mm}, 77.5 \mathrm{~mm}, 59$ $\mathrm{mm}$, de forma esférica.

Uno de los molinos es de andesita, con textura poco porosa, la sección transversal es cóncava. Sus dimensiones son 340x210x85 mm, con una depresión, producida por su uso, de 149x73×25 $\mathrm{mm}$. En el sector de abrasión, se observa el color gris oscuro del interior de la roca, la superficie externa es gris clara por la oxidación de la roca. En el sector lateral de la base de moler se observa pigmento rojo (ocre), blanco y unas motas de color verde. Cabe destacar que fuera del sector central de abrasión hay un sector con picado donde se saltó la pátina. Las otras bases de molino son de sección más plana, y de forma perimetral oval (Fig. 6).

La punta de proyectil es apedunculada, triangular de base recta, elaborada en obsidiana. Las dos preformas de punta de proyectil, también elaboradas en obsidiana, están en sus últimas fases de elaboración (Fig. 7).

Los instrumentos de filo constituyen una muestra de cincuenta elementos. En general, los filos de estos instrumentos fueron trabajados mediante lascados unifaciales directos ultramarginales o marginales tanto paralelos, como escamosos e irregulares. La sección del bisel de los filos de cepillos, raspadores y de por lo menos un filo de los instrumentos compuestos, es abrupto facetado.

Los cepillos son seis, uno de los cuales es de cuarzo y cinco fueron elaborados en sílice. Las formas base utilizadas fueron lascas secundarias. En referencia a las características morfológico- funcionales, podemos distinguir tres grupos de cepillos: con filo semicircular o con dos filos, uno frontal y uno lateral o basal.
Los raspadores son siete, tres de sílice, dos de cuarzo y dos de obsidiana, se utilizaron como formas base lascas medianas. Entre los raspadores podemos distinguir 2 grupos, semicirculares y frontales, ambos elaborados a partir de lascas secundarias, nodulares o primarias. La mayoría presenta lascados unifaciales directos, y en dos raspadores, se observaron lascados bifaciales parcialmente extendidos en la cara dorsal. Cabe destacar que uno de los raspadores es semicircular doble, sus filos son frontales funcionalmente, pero sobre caras alternas (Fig. 8).

El grupo de las raederas está conformado por dos piezas pequeñas. Una elaborada sobre una lasca de arista de sílice y otra sobre una lasca primaria de cuarzo. Ambas presentan lascados unifaciales directos marginales (Fig. 9).

Los cuchillos fueron elaborados a partir de una lasca secundaria y de una lasca primaria, extraídas de guijarros de obsidiana. Sus filos fueron formatizados mediante lascados unifaciales o bifaciales parcialmente extendidos sobre las caras. Cabe destacar que en las márgenes del río Curi Leuvú se observó la presencia de cantos rodados de obsidiana, una fuente de aprovisionamiento muy cercana al sitio, así mismo, debemos tomar en cuenta que los afluentes del Curi Leuvú tienen sus nacientes en volcanes y cerros con formaciones basálticas, como lo son el Cerro Negro, y los volcanes Tromen y Domuyo.

Entre los instrumentos compuestos se destaca la presencia de varios filos con características morfológico-funcionales diferentes. Presentan hasta cinco filos activos con funciones de raspador, muesca, raedera y cuchillo en un mismo instrumento. En algunos casos, el filo de raspador es considerado cepillo, por su tamaño (Aschero, 1983: 273). La muestra está conformada por diez instrumentos, dos de los cuales 


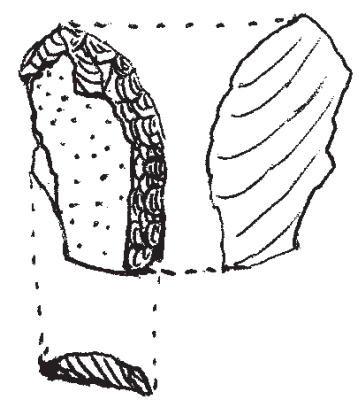

Fig. 9. Raedera.

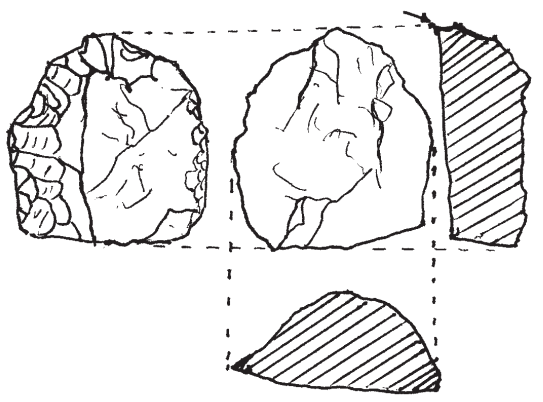

Fig. 10. Instrumento Compuesto. fueron elaborados sobre obsidiana, uno en cuarzo, dos en ópalo y cinco en sílice. Se utilizaron como forma base lascas secundarias, de adelgazamiento y de arista, simple o doble. Técnico-morfológicamente los filos fueron formatizados por lascados unifaciales (directos, inversos o alternos) o bifaciales en la misma pieza. En general, los lascados son marginales, de retoque paralelo corto en el filo de los raspadores, e irregulares o escamosos en los filos de las raederas. Cabe destacar que uno de los extremos presenta lascados bifaciales conformando una punta que pudo constituir una raclette (Fig. 10).

Otros instrumentos destacables son las lascas con rastros de utilización, las cuales conforman una muestra de veintitrés elementos. Los rastros de utilización son lascados y microlascados ultramarginales. Cabe destacar que la mayoría, presenta más de un filo activo. Las materias primas utilizadas son las siguientes: doce lascas de obsidiana, una de cuarzo, siete de sílice y tres basalto. Los filos presentan características morfológico-funcionales múltiples, presentando filos con función de raedera, cuchillo y de raspador. Las lascas varían de tamaño significativamente, entre pequeñas y muy grandes, aunque la mayor parte entra en el módulo de lascas medianas.

Respecto a los rastros de utilización que fueron observados macroscópicamente (con lupa binocular de 400 aumentos) en los filos de los instrumentos con retoques y en las lascas con rastros de utilización, se pudo determinar la presencia de microlascados continuos ultramarginales atenuados, así como astilladuras. Lo cual posiblemente sea consecuencia del trabajo sobre material duro (Aschero 1974, 1982); cabe destacar que se detectaron huellas de corte en diáfisis de material zooarqueológico. En los filos de los instrumentos elaborados en obsidiana, los rastros de utilización son machacados discontinuos ultramarginales en todo el filo. Cabe destacar que en algunos instrumentos de obsidiana se observaron lascados profundos, parcialmente extendidos sobre la cara dorsal.

La actividad de talla en el sitio, muestra la presencia de núcleos (dos de obsidiana, siete de cuarzo y dos de sílice) y desechos de talla (quince de obsidiana, ocho de cuarzo, una de cuarcita, veintinueve de basalto y once de sílice).

\section{CONSIDERACIONES GENERALES}

Los resultados obtenidos hasta el momento, sobre el estudio de los hallazgos realizados en dos campañas de rescate, nos permiten suponer que el sitio Aquihuecó era un cementerio, y que la distribución tanto de los restos óseos humanos como zooarqueológicos así como de los restos materiales se desarrollaron en el marco de un ritual funerario. En el estado actual de avance de las investigaciones del sitio, ésta es considerada como inferencia preliminar y en futuras excavaciones esperamos encontrar elementos que nos permitan contrastar dicha hipótesis. Sin embargo, con los resultados obtenidos hasta el momento consideramos dos opciones. Por un lado, la posibilidad del uso de los instrumentos para la preparación de alimentos a ser ingeridos por quienes participaron del funeral y que los restos de comida fueron depositados como ofrenda. Por otro, que luego de la preparación de los alimentos, los mismos fueron depositados en el entierro como ofrenda. Ambas alternativas son posibles, considerando que se realizó el hallazgo de restos zooarqueológicos quemados y de restos con huellas de corte en asociación directa a los entierros. Debido a que el grado de contemporaneidad de los 
entierros no ha sido determinado aún, podemos suponer que en distintos momentos se realizaron ambas alternativas.

Otro hecho importante que sustenta nuestra hipótesis de la existencia de algún tipo de ritual funerario, es el hallazgo de un fósil de Amonite sp. (impronta) y de un diente de Felis concolor en asociación directa a dos de los entierros, los cuales creemos que fueron depositados como ajuar funerario. Por otra parte, consideramos que las cuentas de valva halladas en asociación directa a uno de los entierros, eran parte de un collar que tenía puesto el individuo al momento de ser enterrado.

Futuras excavaciones sistemáticas en todo el médano nos permitirán ampliar la información sobre este importante sitio y la población que habitaba el NO de Norpatagonia.

\section{AGRADECIMIENTOS}

En los trabajos de campo a los que hace referencia este trabajo colaboraron activamente en 1997, la Sra. Mariana Donadio de Chos Malal, el Sr. Hesler, el Sr. Guagliardo de la Dirección de Cultura de Chos Malal. Agradecemos muy especialmente a la Sra. Silvia Domínguez por su colaboración en las tareas de campo y laboratorio, al Escuadrón 30 Chos Malal de la Gendarmería Nacional por su apoyo logístico, y la colaboración personal del Sargento Ayudante Pedro Torres para las tareas de campo desarrolladas durante el 2003.

Los trabajos que permitieron el desarrollo de este proyecto fueron financiados por la actual Secretaría de Estado de Cultura de la Provincia del Neuquén. Hemos tenido el apoyo permanente del personal de la Dirección Provincial de Archivos y Patrimonio y de su Dirección General de Patrimonio. Un especial agradecimiento a la Lic. Estela Cúneo por sus comentarios, al Prof. Bello por su trabajo de digitalización de figuras, a la Sra. Liliana Martínez por su apoyo en las tareas de laboratorio y a los Sres. Graciela Oviedo y Gabriel Lambrech. Particularmente a la Srta. Cecilia Ronchi por su traducción y comentarios.

\section{BIBLIOGRAFÍA}

ASCHERO, CARLOS A. 1974. Ensayo para una clasificación morfológica de artefactos líticos aplicada a estudios tipológicos comparativos. Informe presentado al Con- sejo Nacional de Investigaciones Científicas y Técnicas, Buenos Aires, MS: 1-83. Argentina.

ASCHERO, CARLOS A. 1983. Ficha y variables para la descripción de desechos de talla: 1-4. Ensayo para una clasificación morfológica de artefactos líticos. MS. Buenos Aires. Argentina.

BUIKSTRA, JANE y DOUGLAS UBELAKER. 1994 Standards for Data Collection from Human Skeletal Remains: pp 15-38. Arkansas Archaeological Survey Research Series (44).

HAJDUK, ADAN. 1991. Las cuentas vítreas del sitio arqueológico Caepe Malal I (departamento Chos Malal, Neuquén) como indicadores temporales. En: Boschín, María Teresa (comp.) Cuadernos de investigación. Arqueología y Etnohistoria de la Patagonia Septentrional, Tandil, IEHS, pp. 36-48.

HAJDUK, ADAN. 1993-1994. Arqueología de la cuenca del río Curi Leuvú. Sitio Caepe Malal I, departamento Chos Malal, provincia del Neuquén. Informe al CONICET, 63 pág. MS.

HAJDUK, ADAN. 1997-1998. Arqueología de la cuenca del río Curi Leuvú. Sitio Caepe Malal I, departamento Chos Malal, provincia del Neuquén. Segundo informe de avance al CONICET, 77 pág., MS.

HAJDUK, ADAN. 1999. Valores Histórico-Culturales. En: Iglesias, G.; A. Pérez; E. Ramilo y J. Salguero: Plan general de Manejo del Parque Provincial Tromen. Provincia de Neuquén. SNAP, Bariloche, pp. 59-70 y figs. MS.

HAJDUK, ADAN. 1999-2000. Arqueología de la cuenca del río Curi Leuvú. Sitio Caepe Malal I, departamento Chos Malal, provincia del Neuquén. Tercer informe de avance informe al CONICET, 130 págs. MS.

HAJDUK, ADAN y ANA M. BISET. 1991. Principales características del sitio Caepe Malal I-Valle del río Curi Leuvú, Departamento Chos Malal (Provincia del Neuquén). Informe preliminar- En: Boschín, María Teresa (comp.) Cuadernos de Investigación. Arqueología y Etnohistoria de la Patagonia Septentrional, Tandil, IEHS, pp. 6-17.

HAJDUK, ADAN y ANA M. BISET. 1996. El sitio arqueológico Caepe Malal I (cuenca del río Curi Leuvú, Departamento Chos Malal, Provincia del Neuquén). En: Gómez Otero, Julieta (comp.) Arqueología. Sólo Patagonia, Puerto Madryn, CENPAT-CONICET, pp. 77-87.

HAJDUK, ADAN y M. J. LEZCANO. 2003. Informe de la campaña realizada en la cuenca media del río Curi Leuvú (departamento Chos Malal, provincia de Neuquén). Presentado a la Subsecretaría de Cultura de Neuquén. MS.

HAJDUK, ADAN; CÚNEO, ESTELA M.; ALBORNOZ, ANA M.; DELLA NEGRA, CLAUDIA E.; NOVELLINO, PAULA S. 2000; Nuevas investigaciones desarrolladas en el sitio Caepe Malal I (cuenca del Curi Leuvú, departamento Chos Malal, Provincia del Neuquén. En: Desde el país de los gigantes. Perspectivas arqueológicas en Patagonia (IV Jornadas de Arqueología de la Patagonia), UNPA (Tomo 1): 297-313. La Plata. Argentina.

ZÁRATE, MARCELO A. 2002. Los ambientes del tardiglacial y Holoceno en Mendoza: 9-43. (Gil, Adolfo F. y Neme, Gustavo A.) En: Entre montañas y desiertos: arqueología del sur de Mendoza. Sociedad Argentina de Antropología. Argentina. 